\title{
Impact of Including Higher Actinides in Fast Reactor Transmutation Analyses
}

B. Forget

M. Asgari

R. Ferrer

S. Bays

September 2007

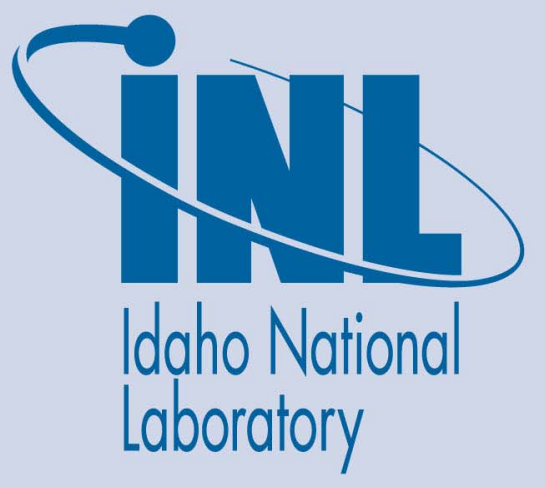

The INL is a U.S. Department of Energy National Laboratory operated by Battelle Energy Alliance 


\section{Impact of Including Higher Actinides in Fast Reactor Transmutation Analyses}
B. Forget
M. Asgari
R. Ferrer
S. Bays

September 2007

\section{Idaho National Laboratory \\ Idaho Falls, Idaho 83415}

Prepared for the

U.S. Department of Energy

Office of Nuclear Energy

Under DOE Idaho Operations Office

Contract DE-AC07-05ID14517 


\section{Impact of Including Higher Actinides in Fast Reactor Transmutation Analyses}

INL/EXT-07-13247

September 2007

Approved by

Benoit Forget, Principal Author

Date

Mehdi Asgari, Peer Reviewer

Date

David W. Nigg, Department Manager

Date 


\section{ABSTRACT}

Previous fast reactor transmutation studies generally disregarded higher mass minor actinides beyond Cm-246 due to various considerations, including deficiencies in nuclear cross-section data. Although omission of these higher mass actinides does not significantly impact the neutronic calculations and fuel cycle performance parameters follow-on neutron dose calculations related to fuel recycling, transportation and handling are significantly impacted. This report shows that including the additional minor actinides in the equilibrium fast reactor calculations will increase the predicted neutron emission by about $30 \%$. In addition a sensitivity study was initiated by comparing the impact of different crosssection evaluation file for representing these minor actinides. 



\section{DISCLAIMER}

This report was prepared as an account of work sponsored by an agency of the United States Government. Neither the United States Government nor any agency thereof, or any of their employees, makes any warranty, express or implied, or assumes any legal liability or responsibility for the accuracy, completeness, or usefulness of any information, apparatus, product, or process disclosed, or represents that its use would not infringe privately owned rights. Reference herein to any specific commercial product, process, or service by trade name, trademark, manufacturer, or otherwise, does not necessarily constitute or imply its enforcement, recommendation, or favoring by the United States Government or any agency thereof. The views and opinions of authors expressed herein do not necessarily state or reflect those of the United States Government or any agency thereof. 



\section{ACKNOWLEDGEMENTS}

The authors would like to thank Steve Piet (INL) and Michael Todosow (BNL) for their contributions. 



\section{CONTENTS}

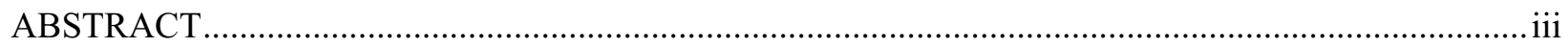

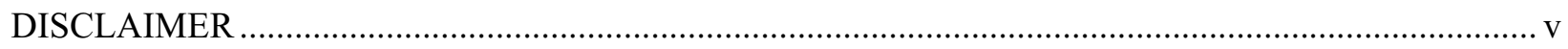

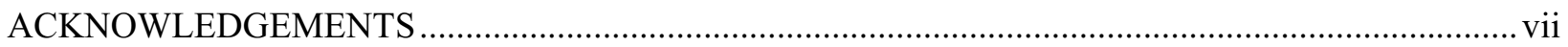

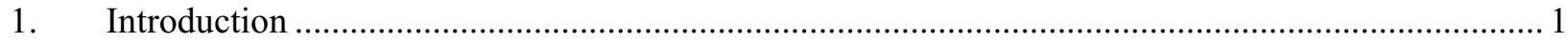

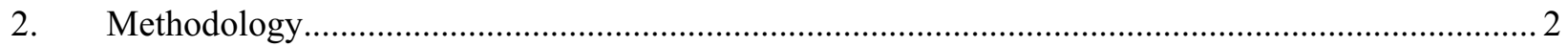

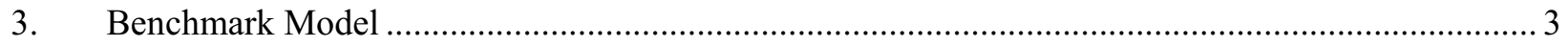

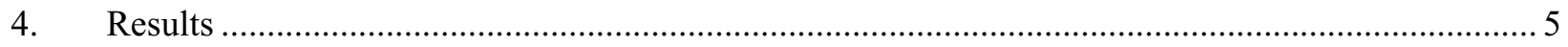

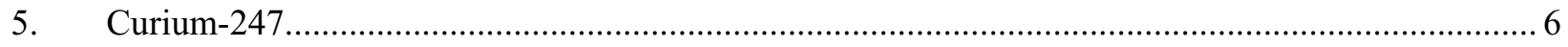

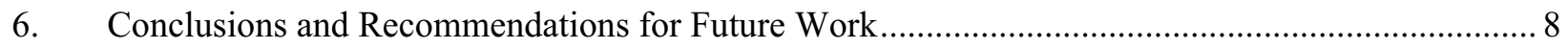

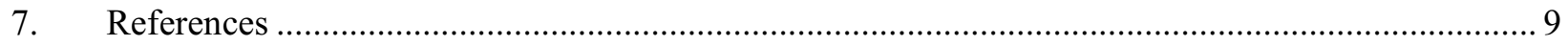




\section{FIGURES}

Figure 2.1: Formation, destruction and decay chain of higher mass minor actinides ............................... 2

Figure 3.1: One Third Symmetric Radial Layout of Metal Fuel CR=0.50 ABR Design........................... 4

Figure 5.1: Point-wise Cross-section Plots of the (n,gamma) Cm-247 Reaction .................................... 7

Figure 5.2: 33 Group Cross-section Data and Reaction Rates in Fast Energy Range .............................. 7 


\section{TABLES}

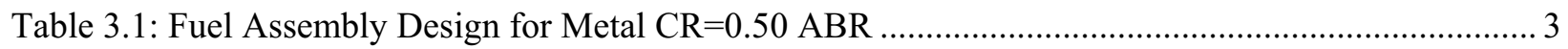

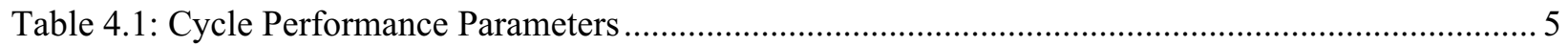

Table 4.2: Total Neutron Emission and Principle Contributors (Neutrons/s per MTHM) ......................... 5

Table 4.3: Mass Variations of Higher Minor Actinides.......................................................................... 6 


\section{Introduction}

Past Advanced Burner Reactor (ABR) neutronic analyses [1-2] have not tracked the minor actinides above $\mathrm{Cm}-246$ in the transmutation chain, primarily because of the small influence on the overall reactor performance and cycle parameters. However, when trying to quantify the neutron emission from the recycled fuel with high minor actinide content, these higher isotopes play an essential role and should be included in the analysis.

In this report, the influence of tracking these minor actinides on the calculated neutron emission is presented. Comparisons were performed on an ABR design with a conversion ratio of 0.5 previously described in references [1-2]. In the studied scenario, the spent nuclear fuel from the current fleet of light water reactors is recycled through the UREX+1a [3] process and used as a feed for the fast reactor.

Also presented is the particular influence of choosing a different evaluated cross section data set to represent the minor actinides above $\mathrm{Cm}-246$. The first representation uses the cross-sections provided by the MCC-2 [4] code for all isotopes, while the second representation uses infinitely diluted ENDF/BVII.0 [5] cross-sections for Cm-247 to Cf-252 and MCC-2 for all other isotopes. 


\section{Methodology}

The analysis was performed on a 1000 MWth reference metallic fuel Advanced Burner Reactor (ABR) with a conversion ratio of 0.5 as described by Hoffman [1]. The DIF3D/REBUS [6-7] code package was used for the equilibrium fuel cycle analysis while utilizing the MCC-2 code as a means to process and self-shield 33-group cross-sections. The decay chain used in REBUS in previous calculations at Idaho National Laboratory (INL) was updated to include the higher minor actinides. A simplified illustration of the added decay chain is presented in Figure 1. Additional nuclear interactions (e.g. (n,alpha), (n,2n), (n,fission)) are included in the model implemented in REBUS.

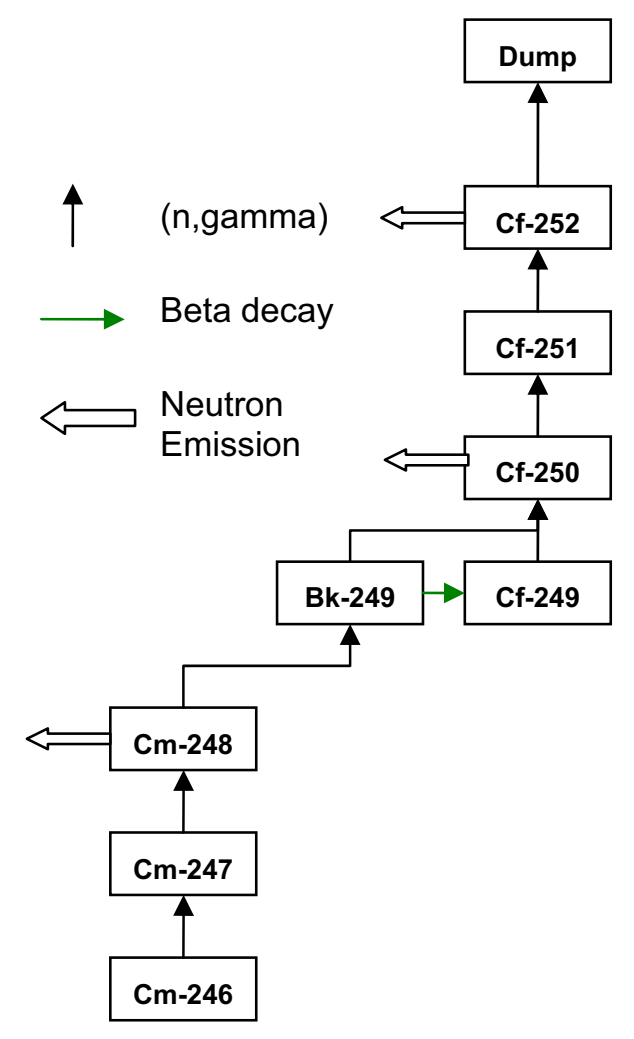

Figure 2.1: Formation, destruction and decay chain of higher mass minor actinides

In Figure 1, the Cm-249 and Cm-250 isotopes were omitted because they do not appear in the MCC-2 libraries. The beta decay half-life of Cm-249 is very short (i.e. 65 minutes) thus it is assumed that the (n,gamma) interaction with Cm-248 produces Bk-249 directly. For the same reason, the Bk-250 isotope was also omitted (beta decay half-life of 3.2 hours), thus an (n,gamma) interaction with Bk-249 will produce $\mathrm{Cf}-250$ directly.

Additionally, a 33 group cross-section set was generated for the higher minor actinides from the latest ENDF/BVII.0 library using NJOY99 [8] with a typical fast reactor spectrum. For consistency purposes in the comparison, the $\mathrm{Cm}-249, \mathrm{Cm}-250$ and $\mathrm{Bk}-250$ isotopes were also omitted. 


\section{Benchmark Model}

The fuel assembly cold dimensions, along with the fuel pin design and volume fractions for the reference metal ABR, are listed in Table 3.1. The original S-PRISM assembly design had 271 pins per assembly, while the assembly designs for the metal $\mathrm{CR}=0.50 \mathrm{ABR}$ has 324 pins per assembly. The reduced thermal conductivity and fuel solidus temperature of higher TRU enriched fuel pins required a larger number of pins per assembly in order to reduce the average linear power to an acceptable limit. The shrinking of the fuel pin diameter also entails using spacer grids instead of wire wrap in the assembly design. The detailed design and geometry of the control rod mechanism, reflector, shield, and gas expansion modules (GEMs) can be found in another report [1]. It suffices to say that these are modeled as homogenous regions and are very similar to those proposed for the S-PRISM design.

Table 3.1: Fuel Assembly Design for Metal CR=0.50 ABR

\begin{tabular}{|l|c|}
\hline & $\mathrm{CR}=0.50$ \\
\hline Assembly pitch, cm & 16.142 \\
\hline Inter-assembly gap, cm & 0.432 \\
\hline Duct outside flat-to-flat, cm & 15.710 \\
\hline Duct material & $\mathrm{HT} 9$ \\
\hline Duct thickness & 0.394 \\
\hline Fuel Pins per Assembly & 324 \\
\hline Spacer Type & $\mathrm{Grid}$ \\
\hline Bond & $\mathrm{Na}$ \\
\hline Core Height, cm & 101.60 \\
\hline Plenum Height, cm & 191.14 \\
\hline Overall Pin Length, cm & 407.04 \\
\hline Fuel Smeared/ Fabrication Density, \% TD & $75 \%$ \\
\hline Pin Diameter, cm & 0.623 \\
\hline Cladding Thickness, cm & 0.0559 \\
\hline Pin Pitch-to-diameter Ratio & 1.293 \\
\hline Vol. Fractions, \%: & \\
\hline Fuel & 22.08 \\
\hline Bond & 7.36 \\
\hline Structure & 26.41 \\
\hline Coolant & 44.15 \\
\hline
\end{tabular}

The radial layout of the metal $\mathrm{CR}=0.50 \mathrm{ABR}$ core consists of three driver fuel regions; the inner, middle, and outer core. A schematic of this layout is shown below in Figure 3.1. The inner core consists of four rows containing a total of 42 assemblies. The middle core consists of two rows containing a total of 66 assemblies with a charge TRU enrichment of 1.25 times that of the inner core. Finally, the outer core consists of a single row containing 36 assemblies with a charge TRU enrichment of 1.50 times that of the inner core. Such an enrichment splitting allows for the flattening of the power distribution. The reflector and shield regions of the core correspond to the last three rows of the core. While the ultimate shutdown and primary control rods are shown in the schematic, these were modeled as fully withdrawn. 

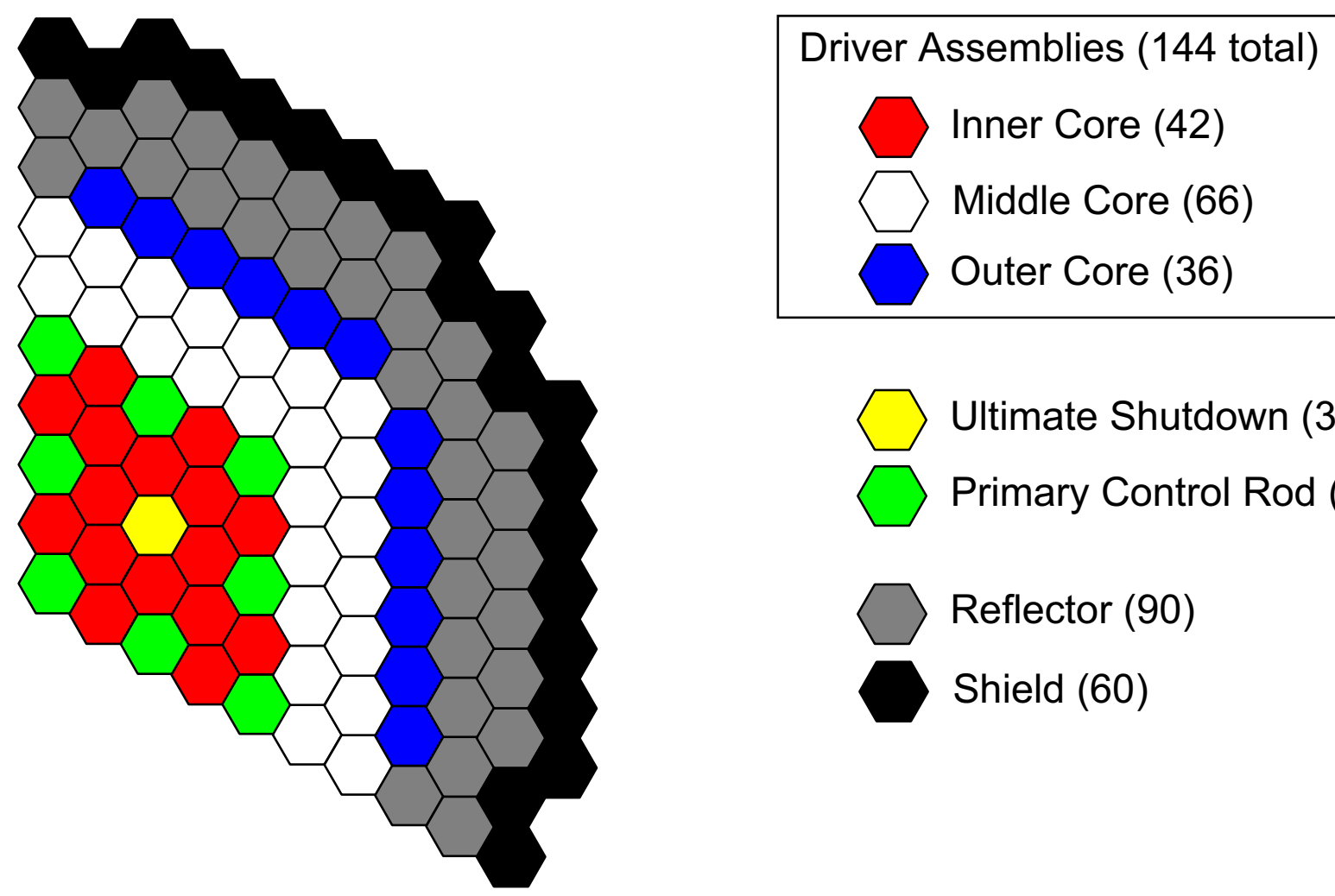

Figure 3.1: One Third Symmetric Radial Layout of Metal Fuel CR=0.50 ABR Design

In this study, the TRU component of LWR SNF is assumed to be separated through aqueous separation $(U R E X+1 a)$ and sent to the fuel fabrication plant to be converted into ABR fuel. The discharged fuel from the reactor is reprocessed through an electrochemical process, and fed back into the fuel fabrication plant. Depleted uranium is assumed to be the only other external feed to provide fuel material to the fuel fabrication plant. The fuel fabrication plant feeds the ABR with the necessary charge isotopic vector. The LWR SNF feed is assumed to come from a PWR with a burnup of $51 \mathrm{GWd} / \mathrm{MTHM}$ that is cooled for 5 years. 


\section{Results}

The cycle performance parameters are presented in Table 4.1. The previous analysis results (MCC-2/Cm-246) are compared to the results with an expanded decay chain from MCC-2 cross sections and ENDF/B-VII cross sections. It should be noted once again that in the ENDFVII case, only the minor actinides beyond $\mathrm{Cm}-246$ come from ENDF/B-VII.

Table 4.1: Cycle Performance Parameters

\begin{tabular}{|c|c|c|c|c|}
\hline & & $\begin{array}{l}\mathrm{MCC}-2 \\
\mathrm{Cm}-246\end{array}$ & $\begin{array}{l}\text { MCC-2 } \\
\text { Cf- } 252\end{array}$ & $\begin{array}{l}\text { ENDFVII } \\
\text { Cf- } 252\end{array}$ \\
\hline \multirow{3}{*}{$\begin{array}{l}\text { Charge Enrichment, } \\
\text { TRU/HM (v/f) }\end{array}$} & IC & $26.8 \%$ & $26.8 \%$ & $26.8 \%$ \\
\hline & $\mathrm{MC}$ & $33.5 \%$ & $33.5 \%$ & $33.5 \%$ \\
\hline & $\mathrm{OC}$ & $40.2 \%$ & $40.2 \%$ & $40.2 \%$ \\
\hline \multirow{3}{*}{ Fuel residence time, cycles } & IC & 6 & 6 & 6 \\
\hline & $\mathrm{MC}$ & 6 & 6 & 6 \\
\hline & $\mathrm{OC}$ & 7 & 7 & 7 \\
\hline Burnup (MWd/kg) & Ave. Driver & 129.7 & 129.6 & 129.6 \\
\hline \multirow{3}{*}{$\begin{array}{l}\text { Peak Fast Fluence } \\
\qquad 10^{23} \mathrm{n} / \mathrm{cm}^{2}\end{array}$} & $\mathrm{IC}$ & 4.0 & 4.0 & 4.0 \\
\hline & $\mathrm{MC}$ & 4.0 & 4.0 & 4.0 \\
\hline & $\mathrm{OC}$ & 3.7 & 3.7 & 3.7 \\
\hline \multicolumn{2}{|c|}{ Cycle length, EFPD } & 216 & 216 & 216 \\
\hline \multirow{2}{*}{$\mathrm{k}$ eff } & BOEC & 1.0283 & 1.0282 & 1.0282 \\
\hline & EOEC & 1.0005 & 1.0005 & 1.0005 \\
\hline
\end{tabular}

As previously assumed, the higher mass minor actinides have negligible influence on the cycle performance parameters. A very small difference can be seen in the beginning of equilibrium cycle (BOEC) $\mathrm{k}$ eff and in the burnup. Additionally, no changes are observed in the decay heat or the photon emission rate because these values are dominated by isotopes below $\mathrm{Cm}-246$, however the same cannot be said about the neutron emission rate. Table 4.2 compares the neutron emission in the fuel charged in the reactor at the beginning of equilibrium cycle in terms of neutrons per second per metric ton of heavy metal charged in the reactor. The table presents the major contributing isotopes to the total neutron emission as well as the total emission generated by the actinides in the fuel.

Table 4.2: Total Neutron Emission and Principle Contributors (Neutrons/s per MTHM)

\begin{tabular}{|l|c|c|c|}
\hline & $\begin{array}{c}\text { MCC-2/ } \\
\text { Cm-246 }\end{array}$ & $\begin{array}{c}\text { MCC-2/ } \\
\text { Cf-252 }\end{array}$ & $\begin{array}{c}\text { ENDFVII/ } \\
\text { Cf-252 }\end{array}$ \\
\hline Cm-242 & $1.6 \mathrm{E} 9$ & $1.6 \mathrm{E} 9$ & $1.6 \mathrm{E} 9$ \\
\hline Cm-244 & $8.1 \mathrm{E} 10$ & $8.1 \mathrm{E} 10$ & $8.1 \mathrm{E} 10$ \\
\hline Cm-246 & $9.5 \mathrm{E} 9$ & $9.5 \mathrm{E} 9$ & $9.5 \mathrm{E} 9$ \\
\hline Cf-250 & 0 & $7.5 \mathrm{E} 9$ & $1.7 \mathrm{E} 10$ \\
\hline Cf-252 & 0 & $1.3 \mathrm{E} 10$ & $3.9 \mathrm{E} 10$ \\
\hline Total & $9.3 \mathrm{E} 10$ & $1.2 \mathrm{E} 11$ & $1.5 \mathrm{E} 11$ \\
\hline
\end{tabular}

An increase of about $30 \%$ is observed when including the higher minor actinides in MCC-2. This increase is attributed mainly to the presence of Cf-250 and Cf-252, which are strong neutron emitters that 
were previously neglected. Using the ENDF/B-VII library for the higher minor actinides increases the neutron emission by $60 \%$ relative to the reference case. This neutron emission increase compared to the MCC- 2 results is due to an increase in the mass of Californium. Table 4.3 presents the mass differences at equilibrium in the higher minor actinides between the MCC-2 and the ENDF/B-VII evaluations in grams per metric ton of heavy metal charged at equilibrium.

Table 4.3: Mass Variations of Higher Minor Actinides

\begin{tabular}{|l|c|c|c|}
\hline & $\begin{array}{c}\text { MCC-2/ } \\
\text { Cf-252 }\end{array}$ & $\begin{array}{c}\text { ENDFVII/ } \\
\text { Cf-252 }\end{array}$ & $\begin{array}{c}\text { Variation } \\
(\mathbf{\% )}\end{array}$ \\
\hline $\mathrm{Cm}-247$ & 89 & 70 & $-21.3 \%$ \\
\hline $\mathrm{Cm}-248$ & 44 & 61 & 38.6 \\
\hline $\mathrm{Bk}-249$ & 4.1 & 5.1 & 24.4 \\
\hline $\mathrm{Cf}-250$ & 0.68 & 1.5 & 120.6 \\
\hline $\mathrm{Cf}-251$ & 0.094 & 0.28 & 197.9 \\
\hline $\mathrm{Cf}-252$ & 0.0055 & 0.017 & 209.1 \\
\hline
\end{tabular}

When comparing the mass variations between the two different evaluations of higher minor actinides, a mass increase is observed for all isotopes except for the $\mathrm{Cm}-247$. This indicates a possible difference in the (n,gamma) cross-section evaluation of Cm-247.

\section{Curium-247}

A closer look at the Cm-247 (n,gamma) cross-section in MCC-2 and ENDF/B-VII.0 revealed that these cross-section data are based on two different and distinct evaluations. Figure 1 illustrates the pointwise cross-section data from the 1976 evaluation that were used in MCC-2 (ENDF/B-VI and earlier releases) and the 1995 evaluation used in ENDF/B-VII.

As illustrated in Figure 5.1, there is a significant difference in the (n,gamma) cross-section in the fast energy range between both evaluations, especially when one considers that the plot is in a log-log scale. 


\section{Cm-247 (n,gamma) - Pointwise Data}

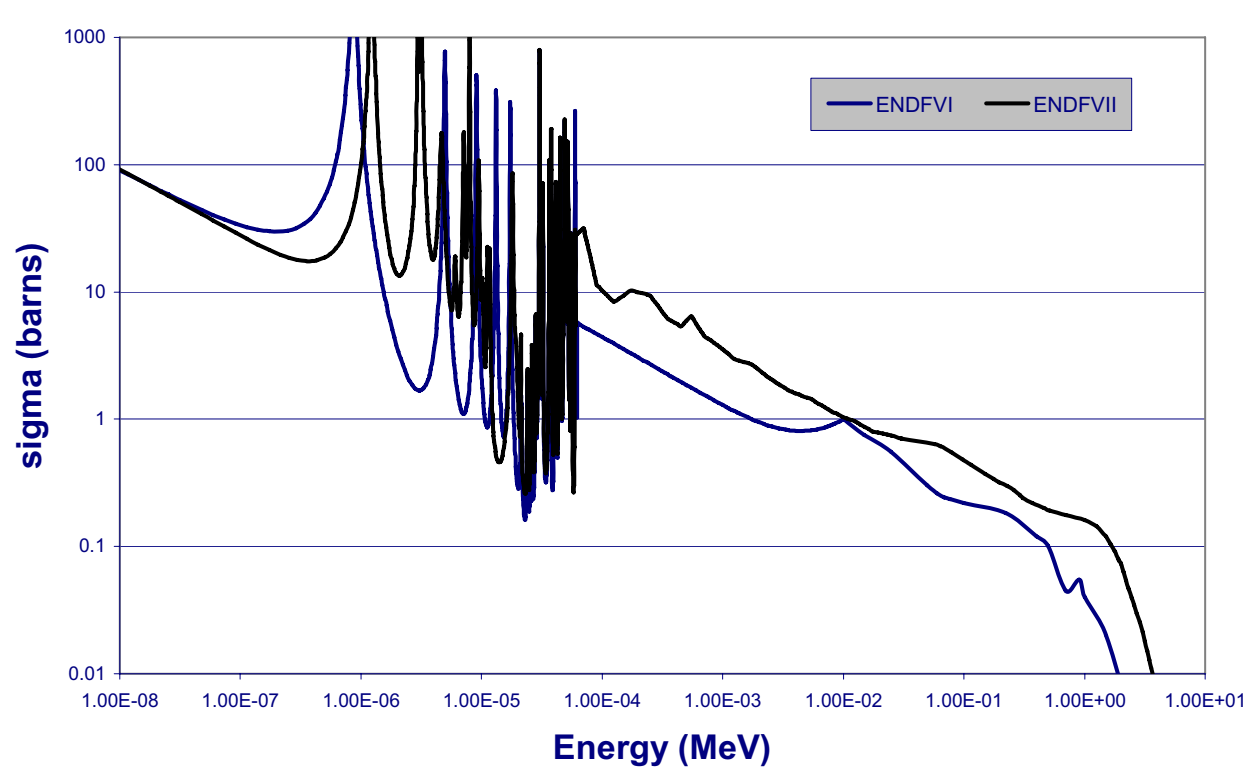

Figure 5.1: Point-wise Cross-section Plots of the (n,gamma) Cm-247 Reaction

Figure 5.2 takes a closer look at the fast energy range by focusing in the $100 \mathrm{eV}$ to $10 \mathrm{MeV}$ range for the 33 group cross-section set.

Cm-247 (n,gamma) and Reaction Rate $-100 \mathrm{eV}$ to $10 \mathrm{MeV}$

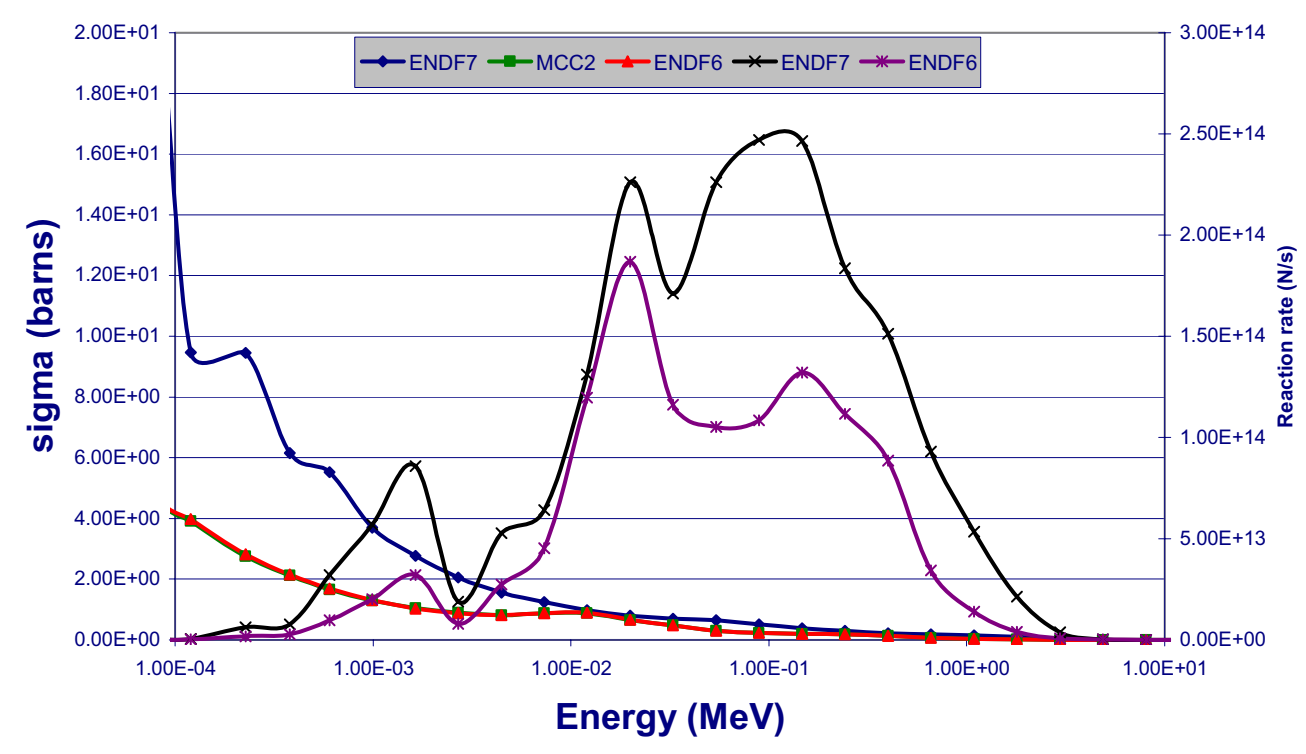

Figure 5.2: 33 Group Cross-section Data and Reaction Rates in Fast Energy Range 
To analyze the effect of the MCC-2 spectrum calculation on the Cm-247 isotope (i.e. shielding effects) the ENDF/B-VI (1976 evaluation) point-wise data was processed with a reference fast spectrum to provide a 33 group data set just like was done for the ENDF/B-VII (1995 evaluation) data set. This crosssection set agreed very well with the MCC-2 data (green and red curve are overlapped in Figure 5.2), thus indicating that the energy self-shielding provided by MCC-2 has minimal effect on this particular isotope for this specific case and that the infinitely dilute approximation is somewhat justified. In addition to the cross-section plot, the (n,gamma) reaction rates for both set of data was also plotted in figure 2. As illustrated, the reaction rate with the ENDF/B-VII data is much larger, thus indicating a reduction of $\mathrm{Cm}$ 247 and a movement up the minor actinide chain.

\section{Conclusions and Recommendations for Future Work}

The addition of the higher minor actinides (above $\mathrm{Cm}-246)$ in the transmutation chain has little to no impact on the neutronics and cycle performance parameters of a fast reactor with minor actinide recycling. However, a significant increase in neutron emission is identified. The different evaluations of the $\mathrm{Cm}-247$ isotope also play a major role in quantifying the neutron emission from the fuel. The 1976 evaluation that was used in ENDF/B-VI and earlier releases presents a much lower (n,gamma) crosssection value for $\mathrm{Cm}-247$ than the 1995 evaluation. This change in cross-section impacts greatly the movement up the actinide chain, thus impacting the neutron emission from Californium isotopes.

Cross-section uncertainty in the higher minor actinides has a significant impact on the uncertainty of neutron emission estimates. Current sensitivity analyses have excluded these minor actinides and have underestimated the neutron emission uncertainty [9-10]. Future studies should include these minor actinides and find reasonable ways to estimate a covariance matrix for this data that is based on the various available evaluations. Finally, it is recommended that a new multigroup cross section data for MCC-2 to be generated based on the latest ENDF/B-VII evaluation data to be utilized in future fast spectrum transmutation analyses. 


\section{References}

1. E.A.Hoffman, W.S.Yang and R.N.Hill, "Preliminary Core Design Studies for the Advanced Burner Reactor over a Wide Range of Conversion Ratios," Argonne National Laboratory, ANLAFCI-177 (2006).

2. R.M.Ferrer, M.Asgari, S.Bays and B.Forget "Computational Neutronics Methods and Transmutation Performance Analyses for Fast Reactors," Idaho National Laboratory, INL-EXT07-12466 (2007).

3. G.F.Vandegrift et al, "Design and demonstration of the UREX+ Process Using Spent Nuclear Fuel," Advances for Future Nuclear Fuel Cycles, Nimes, France, June 21-24 (2004).

4. H.Henryson II. B.J.Toppel, and C.G.Stenberg, "MC'-2: A code to Calculate Fast Neutron Spectra and Multi-Group Cross-Sections," Argonne National Laboratory, ANL-8144 (1976).

5. M.B.Chadwick, "ENDF/B-VII.0: Next Generation Evaluated Nuclear Data Library for Nuclear Science and Technology," Nuclear Data Sheets, 107, 12 (2006).

6. K.L.Derstine, "DIF3D: A Code to Solve One-, Two-, and Three-Dimensional Finite Difference Diffusion Theory Problems," Argonne National Laboratory, ANL-82-64 (1984).

7. B.J.Toppel, “A User's Guide to the REBUS-3 Fuel Cycle Analysis Capability,” Argonne National Laboratory (1983).

8. R.E.MacFarlane and D.W.Muir, "The NJOY nuclear data processing system, version 91," Tech. Rep. LA-12740-M, Los Alamos National Lab, NM (1994).

9. G. Aliberti, G. Palmiotti, M. Salvatores and C.G. Stenberg, "Impact of Nuclear Data Uncertainties on Transmutation of Actinides in Accelerator-Driven Assemblies," Nuclear Science and Engineering, 146, 13-50 (2004).

10. G.Aliberti, G. Palmiotti, M. Salvatores, T.K. Kim, T.A. Taiwo, M. Anitescu, I. Kodeli, E. Sartori, J.C. Bosq, J. Tommasi, "Nuclear data sensitivity, uncertainty and target accuracy assessment for future nuclear systems," Annals of Nuclear Energy, 33, 700-733 (2006). 